\title{
The Influence of Digestive Dysfunctions on Quality of Life in Parkinson Disease
}

\author{
OANA CRICIOTOIUㄴ, IULIA-DIANA STANCA ${ }^{2 *}$, DANIELA-GABRIELA GLAVAN ${ }^{3}$, ROXANA MIRELA LATEA ${ }^{4}$, ADRIAN MITA ${ }^{5}$, \\ VERONICA CALBOREAN ${ }^{1}$, VICTOR GHEORMAN ${ }^{3}$, ION UDRISTOIU ${ }^{3}$, ANDA LORENA DIJ MARESCU ${ }^{6}$, DRAGOS VIRGIL DAVITOIU7, \\ DAN IONUT GHEONEA ${ }^{8}$ \\ ${ }^{1}$ University of Medicine and Pharmacy of Craiova, Doctoral School, 2 Petru Rares Str., 200349, Craiova, Romania \\ 2 University of Medicine and Pharmacy of Craiova, Faculty of Medicine, Department of Neurology, 2 Petru Rares Str., 200349, \\ Craiova, Romania \\ ${ }^{3}$ University of Medicine and Pharmacy of Craiova, Faculty of Medicine, Department of Psychiatry, 2 Petru Rares Str., 200349, \\ Craiova, Romania \\ ${ }^{4}$ Municipal Hospital Calafat, Department of Neurology, 5 Traian Str., 205200, Calafat, Romania \\ ${ }^{5}$ University of Medicine and Pharmacy of Craiova, Faculty of Medicine, Department of Internal Medicine, 2 Petru Rares Str., \\ 200349, Craiova, Romania \\ ${ }^{6}$ University of Medicine and Pharmacy of Craiova, Obstretics-Gynecology Department, Filantropia Clinical Hospital of Craiova \\ , 1 Filantropiei Str., 200143, Craiova, Romania \\ 7 University of Medicine and Pharmacy of Bucharest, Surgery Department, Clinical Emergency Hospital Sf. Pantelimon Bucharest, \\ 340-343 Pantelimon Road, 021659, Bucharest, Romania \\ ${ }^{8}$ University of Medicine and Pharmacy of Craiova, County Hospital of Craiova, Gastroenterology Department, 1 Tabaci Str., \\ 200642, Craiova, Romania
}

\begin{abstract}
As a part of non-motor symptoms in Parkinson's disease (PD), the dysfunctions of the gastrointestinal tract are frequent, being a major complain in the majority of the patients. The aim of our study was to assess the impact of digestive dysfunctions on quality of life in Parkinson's disease. We included in this study 60 patients with PD, with a disease severity which varied between 2 and 5 on Hoehn and Yahr Scale. Our results showed a low correlation between digestive dysfunctions and the severity of the disease, but a statistically significant correlation between quality of life and the stage of the disease. Also, we observed a statistically significant correlation between digestive dysfunctions and quality of life. Our study revealed that the frequency of digestive dysfunction has correlated with a poor quality of life in any stage of the disease.
\end{abstract}

Keywords: Parkinson's disease, digestive dysfunctions, quality of life

In all stages of Parkinson's disease, gastrointestinal dysfunctions are frequent, being a major complain in the majority of the patients [1].

Being a part of non-motor symptoms in Parkinson's disease (PD), the dysfunctions of the gastrointestinal tract include symptoms such as: sialorrhea, dysphagia, delayed gastric emptying, problems with absorption and constipation [2]. Often, digestive dysfunctions can be manifested even prior to the Parkinson's disease diagnosis, during in so-called pre-tor phase of the disorder and could serve as prodromal markers of this early non-motor phase [3].

These conditions are quite distressing for the patients with Parkinson's disease, sometimes with severe consequences to the patient's quality of life and causing negatively influences on the antiparkinsonian therapy. As an example, delayed gastric emptying is an important cause of unexpected motor fluctuations [4].

The pathophysiologic basis of this dysfunction involves both central and enteric neurons systems and is due - in part - to the presence of Lewy body both in dorsal motor nucleus of the vagus nerve which supplies parasympathetic innervation of the gut from the distal esophagus to the left colonic flexure, as well as in the intramural Meissner and Auerbach plexuses of the enteric nervous system [5].

Weight loss is common, but poor understood in people with PD. Dysphagia can results from dysfunction of the mouth, pharynx or esophagus and may predispose patients to aspiration [6] .
Gastroparesis can produce different symptoms in PD patients it may cause erratic absorption of the antiparkinsonian drugs [ 7]. Bowel dysfunction can consist of slowed colonic transit with reduced bowel-movement frequency and difficulty with the act of defecation and incomplete emptying [8].

Although digestive dysfunctions occur in the majority of the patients with PD, they are often unrecognized [9].

Early detection and effective interventions on these conditions can help prevent the serious consequences in quality of life [10].

The aim of our study was to assess the impact of digestive dysfunctions on quality of life in Parkinson's disease.

\section{Experimental part}

Methods and materials

We studied 60 patients with clinical diagnosis of Parkinson's disease established by Movement Disorder Society Clinical Diagnostic Criteria for Parkinson's disease [11].

The patients were eligible for inclusion in this study if they had at least 8 years of education and at least 25 points on Mini Mental State Examination (MMSE) [12].

We excluded patients with a history or evidence of other medical condition that could interfere with quality of life.

In our group the median age was 67.03 with a standard deviation of 7.7. 22 were women and 38 males. Disease 
severity was evaluated with Hoehn and Yahr staging scale which variated from 2 to 5 [13].

The digestive dysfunction was evaluated using the digestive domain of self-assessment Non-motor Symptoms Questionnaire for Parkinson's Disease (NMSQ) [14].

The NMSQ is recommended for use in Parkinson's disease patients to assess the non-motor symptoms. It is a self-assessing instrument that includes 30 questions covering 10 different domains ranging from gastrointestinal to miscellaneous. The gastrointestinal domain is composed of dribbling of saliva, ageusia, dysphagia or choking, vomiting or nausea, constipation, unsatisfactory voiding of bowel and fecal incontinence. This questionnaire must be completed by the patient, checking the no or yes box. We rated 0 point if the patient's answer was no and 1 point if the patient's answer was yes.

To evaluate quality of life $(\mathrm{Q} O \mathrm{~L})$ we used 8-item Parkinson's Disease Questionnaire (PDQ-8) [15].

PDQ -8 is a disease-specific quality of life tool. The patient is asked how often she/he experienced a certain event due to PD. Rating was made on a five points scale from 0 points never to 4 points always. This instrument consists of 8 domains that assess mobility, activity of daily living, stigma, social support, cognition, communication and bodily discomfort. The score was converted to a 0 - 32 points scale with higher score indicated a poor quality of life.

The Unified Parkinson's Disease Rating Scale (UPDRS) Part III, for motor evaluation, was used to measure motor fluctuation [5].

This scale is an instrument with 27 items which assessed motor function related to tremor, rigidity, posture and bodily movement. Scores range from 0 to 108 points and higher scores indicate lower motor functioning.

The statistical analysis was made using IBM SPSS Statistics V20.

We performed both descriptive and exploratory data analysis. For correlation we used Pearson R test, with the statistically significance established at 95\%, $p<0.05$.

\section{Results and discusions}

Analysis of the gastrointestinal domain of NMSQ relieved an asymmetrical distribution of the digestive dysfunction in our patients.

Constipation, ageusia and drooling of saliva have dominated the digestive items in our sample.

The Hoehn \& Yahr stage showed a poor correlation when compared with the digestive dysfunctions and did nothave a statistical significance $p=0.08$ (table 1, fig. 1).

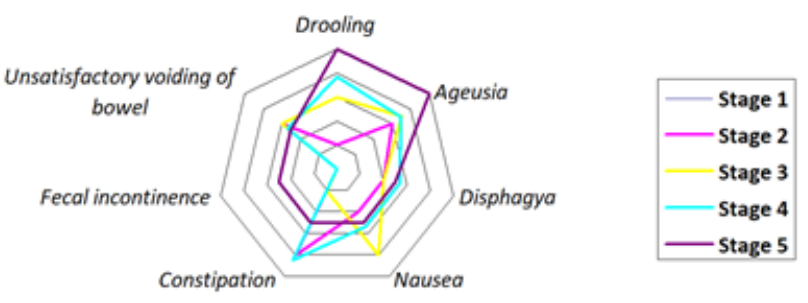

Fig. 1.Frequency of digestive dysfunction

On the other side the stage of the disease and QoL had a positive, statistically significant correlation with $p=0.01$. Analysis of PDQ-8 items reveled a higher impairment of the activity of daily living even in condition of a sustained social support (table 2, fig. 2)

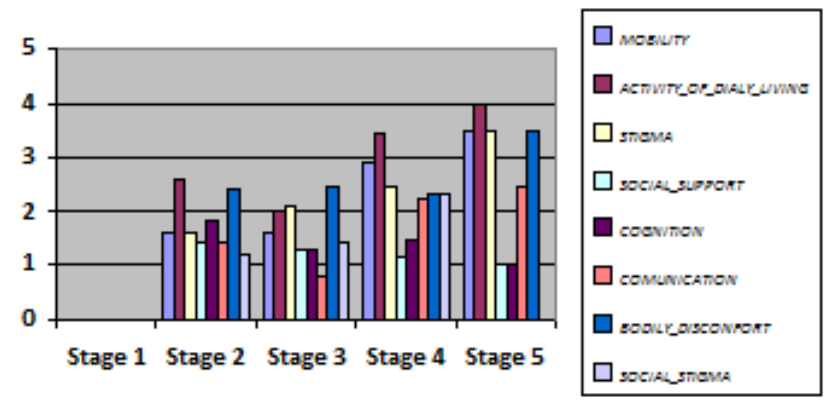

Fig. 2. Distribution of the PDQ8 domains

\section{Correlations}

\begin{tabular}{|ll|r|r|}
\hline & \multicolumn{1}{|c|}{$\begin{array}{c}\text { Digestive_sy } \\
\text { mptoms }\end{array}$} & \multicolumn{1}{c|}{ HY } \\
\hline Digestive_symptoms & Pearson Correlation & 1 & .223 \\
& Sig. (2-tailed) & & .086 \\
& $\mathrm{~N}$ & 60 & 60 \\
\hline $\mathrm{HY}$ & Pearson Correlation & .223 & 1 \\
& Sig. (2-tailed) & .086 & \\
& $\mathrm{~N}$ & 60 & 60 \\
\hline
\end{tabular}

Table 1

CORRELATION BETWEEN DIGESTIVE DYSFUNCTION AND HOEHN \& YAHR STAGE
Correlations

\begin{tabular}{|c|c|c|c|}
\hline & & $\mathrm{HY}$ & PDQ39 \\
\hline \multirow[t]{3}{*}{$\overline{\mathrm{HY}}$} & Pearson Correlation & 1 & .329 \\
\hline & Sig. (2-tailed) & & .012 \\
\hline & $\mathrm{N}$ & 60 & 58 \\
\hline \multirow[t]{3}{*}{ PDQ39 } & Pearson Correlation & $.329^{\prime}$ & 1 \\
\hline & Sig. (2-tailed) & .012 & \\
\hline & $\mathrm{N}$ & 58 & 1048571 \\
\hline
\end{tabular}

Table 2

CORRELATION BETWEEN HOEHN \&YAHR STAGE AND QOL 


\begin{tabular}{|ll|r|r|}
\hline & \multicolumn{1}{|c|}{$\begin{array}{c}\text { Digestive_sy } \\
\text { mptoms }\end{array}$} & \multicolumn{1}{c|}{ PDQ8 } \\
\hline Digestive_symptoms & Pearson Correlation & 1 & $.395^{\prime \prime}$ \\
& Sig. (2-tailed) & & .002 \\
& $\mathrm{~N}$ & 60 & 60 \\
\hline PDQ8 & Pearson Correlation & $.395^{\text {"N }}$ & 1 \\
& Sig. (2-tailed) & .002 & \\
& $\mathrm{~N}$ & 60 & 60 \\
\hline
\end{tabular}

Table 3

CORRELATION BETWEEN DIGESTIVE SYMPTOMS AND QOL

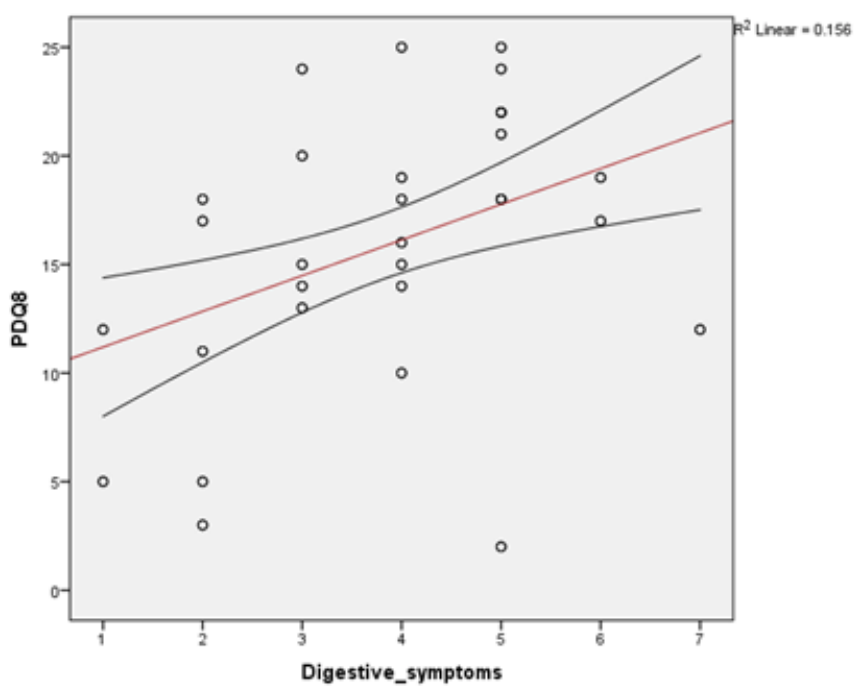

Fig. 3. Correlation between digestive symptoms and QoL

We performed a Pearson correlation between the digestive domain of NMSQ and the quality of life assessed with PDQ-8.

There was a positive correlation between them with a statistic significance $>95 \%, p=0.002$ (table 3, fig. 3)

Even if we have determinate that there is a positive correlation between the gastrointestinal dysfunctions and QoL we also had just a partial correlation. In this way we controlled whether the severity of the disease had an influence on this correlation. In the table below we can see that there was not a significant influence of the $H \& Y$ stage on the correlation between digestive symptoms and PDQ-8and there is still a statistically significant correlation between the both of them (table 4).

Nowadays, there is no cure or treatment to stop the evolution of Parkinson's disease, but we treat people, not diseases and it is important to improve as much as we can the quality of life of these patients. Many studies report that, in most of the time, the non-motor symptoms have a high influence on the QoL [15].

Analysis of $\alpha$-synuclein showed that the digestive tract might have a contribution to Parkinson's etiology and progression [16].

The digestive symptoms are present from the early stages of the disease, being among the prodromal markers of Parkinson's disease [3].

In our study drooling of saliva, ageusia and constipation had the higher prevalence among gastrointestinal symptoms. In the literature, constipation is the most common digestive symptom followed by drooling of saliva [17].

Like our results, many other studies concluded that there is a codependence between the digestive dysfunction and impairment of quality of life $[18,19]$.
Table 4
CORRELATION BETWEEN DIGESTIVE SYMPTOMS AND QoL WHEN CONTROLLING FOR H\&Y STAGE

Correlations

\begin{tabular}{|ll|r|r|}
\hline \multicolumn{2}{|c|}{ Control Variables } & $\begin{array}{c}\text { Digestive_sy } \\
\text { mptoms }\end{array}$ & \multicolumn{1}{c|}{ PDQ8 } \\
\hline HY Digestive_symptoms & Correlation & 1.000 & .349 \\
& Significance (2-tailed) & .007 \\
& df & 0 & 57 \\
\hline PDQ8 & Correlation & .349 & 1.000 \\
& Significance (2-tailed) & .007 &. \\
& df & 57 & 0 \\
\hline
\end{tabular}

\section{Conclusions}

The frequency of digestive dysfunction has correlated with a poor quality of life in our sample. This trend was maintained regardless the severity of the disease.

\section{References}

1. KLINGELHOEFER, L., AND REICHMANN, H., The Gut and Nonmotor Symptoms in Parkinson's Disease, International Review of Neurobiology, vol. 134, 2017, p. 787-809.

2. LECLAIR-VISONNEAU, L., MAGY, L., VOLTEAU, C., CLAIREMBAULT, T., LE DILY, S., PRETERRE, C., PEYRE, A., DAMIER, P., NEUNLIST, M., PEREON, Y., AND DERKINDEREN, P., Heterogeneous pattern of autonomic dysfunction in Parkinson's disease, Journal of Neurology, vol. 265, 2018, p. 933-941.

3.MAREK, K., ADLER, C. H., LIEPELT-SCARFONE, I., DEUSCHL, G., BERG, D., LANG, A. E., CHAN, P., POEWE, W., OLANOW, C. W., BLOEM, B. R., HALLIDAY, G., GASSER, T., JOSEPH, L., DUBOIS, B., GOETZ, C. G., POSTUMA, R. B., OBESO, J., OERTEL, W., LITVAN, I., AND STERN, M., MDS research criteria for prodromal Parkinson's disease, Movement Disorders, vol. 30, 2015, p. 1600-1611.

4.RAMPRASAD, C., DOUGLAS, J. Y., AND MOSHIREE, B., Parkinson's Disease and Current Treatments for Its Gastrointestinal Neurogastromotility Effects, Current Treatment Options in Gastroenterology, vol. 16, 2018, p. 489-510.

5.SCHEPERJ ANS, F., AHO, V., PEREIRA, P. A. B., KOSKINEN, K., PAULIN, L., PEKKONEN, E., HAAPANIEMI, E., KAAKKOLA, S., EEROLA-RAUTIO, J., POHJA, M., KINNUNEN, E., MURROS, K., AND AUVINEN, P., Gut microbiota are related to Parkinson's disease and clinical phenotype, Movement Disorders, vol. 30, 2015.

6.MATSUMOTO, H., SENGOKU, R., SAITO, Y., KAKUTA, Y., MURAYAMA, S., AND IMAFUKU, I., Sudden death in Parkinson's disease: A retrospective autopsy study, Journal of the Neurological Sciences, vol. 343, 2014, p. 149-152.

7.TOPOR, G., NECHITA, A., DEBITA, M., CIUPILAN, C., AND AXENTE, E. R., General and Particular Structural Characteristics of Acetylsalicylic Acid - Aspirine Chemical properties,Rev. Chim. (Bucharest), 70, no. 1, 2019, p. 248-253.

8.HINKLE, J. T., PEREPEZKO, K., MILLS, K. A., MARI, Z., BUTALA, A., DAWSON, T. M., PANTELYAT, A., ROSENTHAL, L. S., AND PONTONE, G. M., Dopamine transporter availability reflects gastrointestinal dysautonomia in early Parkinson disease, Parkinsonism \& Related Disorders, vol. 55, 2018, p. 8-14.

9.GOLDMAN, J. G., AND POSTUMA, R., Premotor and nonmotor features of Parkinson $1 / 4$ s disease, Current Opinion in Neurology, vol. 27, 2014, p. 434-441. 
10.TAKAHASHI, K., KAMIDE, N., SUZUKI, M., AND FUKUDA, M., Quality of life in people with Parkinson's disease: the relevance of social relationships and communication, Journal of Physical Therapy Science, vol. 28, 2016, p. 541-546.

11.POSTUMA, R. B., BERG, D., STERN, M., POEWE, W., OLANOW, C. W., OERTEL, W., OBESO, J., MAREK, K., LITVAN, I., LANG, A. E., HALLIDAY, G., GOETZ, C. G., GASSER, T., DUBOIS, B., CHAN, P., BLOEM, B. R., ADLER, C. H., AND DEUSCHL, G., MDS clinical diagnostic criteria for Parkinson's disease, Movement Disorders, vol. 30, 2015, p. 15911601.

12.SCHRAG, A., JAHANSHAHI, M., AND QUINN, N., What contributes to quality of life in patients with Parkinson's disease?, Journal of Neurology Neurosurgery and Psychiatry, vol. 69, 2000, p. 308-312.

13.J ENKINSON, C., CLARKE, C., GRAY, R., HEWITSON, P., IVES, N., MORLEY, D., RICK, C., WHEATLEY, K., AND WILLIAMS, A., Comparing results from long and short form versions of the Parkinson's disease questionnaire in a longitudinal study, Parkinsonism \& Related Disorders, vol. 21, 2015, p. 1312-1316.

14.TODOROVA, A., JENNER, P., AND RAY CHAUDHURI, K., Non-motor Parkinson's: integral to motor Parkinson's, yet often neglected., Practical neurology, vol. 14, 2014, p. 310-22.
15.BREEN, K. C., AND DRUTYTE, G., Non-motor symptoms of Parkinson's disease: the patient's perspective, Journal of Neural Transmission, vol. 120, 2013, p. 531-535.

16.MUKHERJ EE, A., BISWAS, A., AND DAS, S. K., Gut dysfunction in Parkinson's disease, World J ournal of Gastroenterology, vol. 22, 2016, p. 5742.

17.CHAUDHURI, K. R., HEALY, D. G., SCHAPIRA, A. H., and National Institute for Clinical Excellence, Non-motor symptoms of Parkinson's disease: diagnosis and management, The Lancet Neurology, vol. 5, 2006, p. 235-245.

18.GALCEAVA OANA, MITA ADRIAN, GIURGIULESCU LIGIA, LATEA ROXANA, T., AND VALERICA, GHEONEA DAN, S. D., Correlation between mood and behavioral disorders and quality of life in patients with Parkinson's disease, MDS Volume 33 Supplement 2, vol. 33, 2018, p. 821-822.

19.GHEORMAN, V., MILITARU, F., CALBOREAN, V., GHEORMAN, L. M., CHIRITA, A. L., MITA, A., GALCEAVA, O., GHEORMAN, V., STANCA, D., AND UDRISTOIU, I., Clinical and biochemical considerations regarding stress and arrhythmic risk in patients with chronic viral liver diseases, Rev. Chim. (Bucharest), 69, no. 4, 2018, p. 881-885.

Manuscript received: 12.11 .2018 